\title{
Theoretical Investigation of Performance Improvement in R.O. Plant with Different Membrane
}

\author{
Iftikarahamad H. Patel ${ }^{1}$, Amit D. Nale ${ }^{2}$, Sandesh N. Rathod ${ }^{3}$, Shubham R. Sawane ${ }^{4}$, Ashish P. Barge ${ }^{5}$ \\ Assistant Professor, Mechanical Engineering Department, Shivnagar Vidya Prasarak Mandal's C. O. E. Malegaon (bk), \\ Baramati, India ${ }^{1}$
}

Graduate Student, Mechanical Engineering Department, Shivnagar Vidya Prasarak Mandal's C. O. E. Malegaon (bk), Baramati, India ${ }^{2,3,4,5}$

\begin{abstract}
Reverse osmosis (RO) is a water purification technology that uses a semi permeable membrane to remove ions, molecules, and larger particles from water. A reverse osmosis semi-permeable membrane is used which allows the passage of water molecules but not the majority of dissolved salts, organics, bacteria and pyrogens. Reverse Osmosis (RO) is a membrane based process technology to purify water by separating the dissolved solids from feed stream resulting in permeate and reject stream for a wide range of applications in domestic as well as industrial applications. In the present sugar factory uses cartridge filtered water for boiler but it is harmful to boiler because it not remove total silica content, salts, more hardness, organic matter, various bacteria. To remove the impurities of water the size of membrane is optimized.
\end{abstract}

Keywords: Reverse Osmosis, membrane, element, element vessel, total dissolve solids.

\section{INTRODUCTION}

Osmosis is a naturally occurring phenomenon and one of the most important processes in nature. It is a process where a weaker saline solution will tend to migrate to a strong saline solution as shown in fig.1. Below is a diagram which shows how osmosis works. A solution that is less concentrated will have a natural tendency to migrate to a solution with a higher concentration.

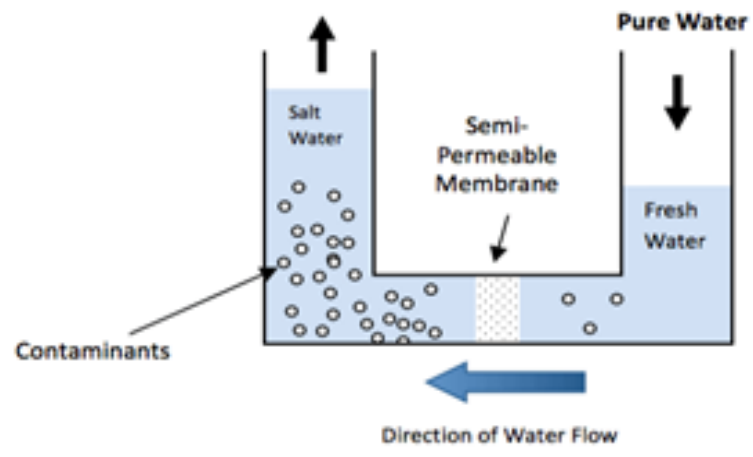

Fig. 1. Basic osmosis process

Reverse Osmosis is the process of Osmosis in reverse. Whereas Osmosis occurs naturally without energy required, to reverse the process of osmosis you need to apply energy to the more saline solution. A reverse osmosis membrane is a semi-permeable membrane that allows the passage of water molecules but not the majority of dissolved salts, organics, bacteria and pyrogens.
However, you need to 'push' the water through the reverse osmosis membrane by applying pressure that is greater than the naturally occurring osmotic pressure in order to desalinate (demineralise or deionise) water in the process, allowing pure water through while holding back a majority of contaminants. A semi-permeable membrane as shown in fig. 2 is a membrane that will allow some atoms or molecules to pass but not others.

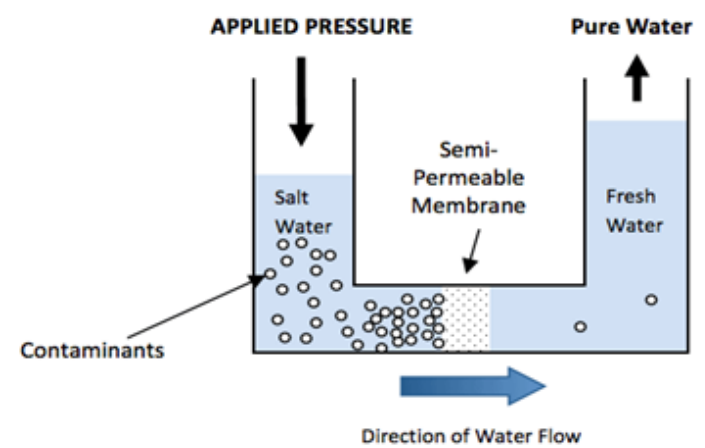

Fig.2. Working of reverse osmosis

Reverse osmosis (RO) is a water purification technology that uses a semi permeable membrane to remove ions, molecules, and larger particles from water. In reverse osmosis, an applied pressure is used to overcome osmotic pressure, a colligative property, that is driven by chemical potential differences of the solvent, a thermodynamic 
IARJSET

parameter. Reverse osmosis can remove many types of C. Membrane Characteristics:

dissolved and suspended species from water, including The membrane should be inexpensive, have longer and bacteria, and is used in both industrial processes and the stable life. Membrane should be easily manufactured with production of potable water. The result is that the solute is good salt rejection i.e. slightly permeable to salt. They retained on the pressurized side of the membrane and the should have high water flux i.e. highly permeable to water pure solvent is allowed to pass to the other side. To be and less susceptible to fouling. They should permit the "selective", this membrane should not allow large flow of large amounts of water through the membrane molecules or ions through the pores (holes), but should relative to the volume they occupy. The membrane should allow smaller components of the solution (such as solvent chemically, physically and thermally stable in saline molecules) to pass freely.

The RO system includes a set of RO membrane elements, housed in pressure vessels that are arranged in a design manner. A high-pressure pump is used to feed the water to pressure vessels. The RO system is usually designed for continuous operation and the operating conditions are constant with time. The feed flow is divided to permeate and concentrate flow. RO system becoming more popular in the home market as homeowners are increasingly concerned about contaminants that affect their health, as well as about non-hazardous chemicals that affect the taste, odour, or colour of their drinking water. In industries this process is used to reduce the hardness, salts from the water.

\section{A. Scope of Work:}

Water is used in boiler for generating steam. If this water contains more contaminations then there may be problems like scale formation and hence it becomes harmful to system. Reverse osmosis is an effective method of reducing the concentration of total dissolved solids (TDS) and many impurities found in water and it improve system performance.

\section{B. Reverse Osmosis Process Description:}

The RO process is simple in design consisting of feed, permeate and reject stream. For feed water it is necessary to provide pretreatment in order to remove inorganic solids and suspended solid and using high pressure pump given feed through semipermeable membrane. Depending upon the permeate where it is used necessary post treatment is given. A schematic diagram of the RO process is shown figure 3 .

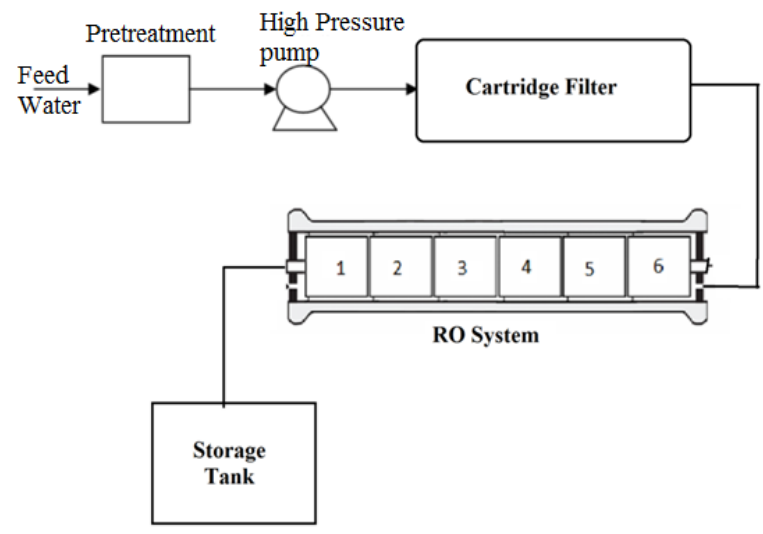

Fig.3 Setup for RO process pressures and variable feed water quality.

\section{LITERATURE REVIEW}

Barbara Kneen, Ann Lemley and Linda Wagnet et. al. [1] focused on Reverse osmosis treatment which is used to reduces the concentration of dissolved solids, including a variety of ions and metals and very fine suspended particles such as Aluminium, Calcium, Carbonate, Chloride, Fluoride, Iron, Lead, Magnesium, Potassium, Sulphate, that may be found in water. An RO device may be installed to reduce the all above impurities. RO also removes certain organic contaminants, some detergents, and specific pesticides.Reverse osmosis will not remove all contaminants from water. Dissolved gases such as oxygen and carbon dioxide pass through RO membranes into the treated water. Unfortunately, hydrogen sulphide gas, with its notorious odour of rotten eggs, also passes through the RO membrane. $\mathrm{RO}$ in general is not a very effective treatment for trihalomethanes (THMs), some pesticides, solvents, and other volatile organic chemicals (VOCs).However, RO systems can be certified by NSF for VOCs, THMs, and several pesticides and solvents if the contamination is not too high. If the water source is severely polluted or untreatable, a public water supply or a reliable private water source must be used.

In the reverse osmosis process a cellophane-like membrane separates purified water from contaminated water. An understanding of osmosis is needed before further describing RO. Osmosis occurs when two solutions containing different quantities of dissolved chemicals are separated by a semi permeable membrane (allowing only some compounds to pass through). Osmotic pressure of the dissolved chemical causes pure water to pass through the membrane from the dilute to the more concentrated solution. There is a natural tendency for chemicals to reach equal concentrations on both sides of the membrane. In reverse osmosis, water pressure applied to the concentrated side forces the process of osmosis into reverse. Under enough pressure, pure water is "squeezed" through the membrane from the concentrated to the dilute side. Salts dissolved in water as charged ions are repelled by the RO membrane. Treated water is collected in a storage container. The rejected impurities on the concentrated side of the membrane are washed away in a stream of wastewater, not accumulated as on a traditional filter. The RO membrane also functions as an ultra 
IARJSET

filtration device, screening out particles, including micro organisms that are physically too large to pass through the membrane's pores. RO membranes can remove compounds in the 0.0001 to 0.1 micron size range (thousands of times smaller than a human hair). Although the reverse osmosis process is simple, a complete water treatment system is often complex, depending on the quality of the incoming water before treatment and the consumer's needs. Most home RO systems are point-ofuse (POU) units placed beneath the kitchen sink to treat water used for cooking and drinking. Point-of-entry (POE) systems that treat all the water entering the household are more expensive to purchase and operate than POU systems.

Sunil J. Kulkarni, Pallavi M. Kherde et. al. [2] told importance of various membrane separation techniques. Nowadays membrane separation techniques are becoming more and more important because of separation efficiency and purity of water for industrial work. He told that membranes are generally classified as isotropic or anisotropic. Isotropic membranes are uniform in composition and physical nature across the cross-section of the membrane. Anisotropic membranes are non-uniform over the membrane cross-section, and they typically consist of layers which vary in structure and/or chemical composition.

Isotropic membranes can be divided into various subcategories. For example, isotropic membranes may be micro porous. Micro porous membranes are often prepared from rigid polymeric materials with large voids that create interconnected pores. The most common micro porous membranes are phase inversion membranes. These are produced by casting a film from a solution of polymer and solvent and immersing the cast film in a no solvent for the polymer. Most polymers used in such applications are hydrophobic, so water is the most common no solvent. Upon contact with water, the polymer precipitates to form the membrane. Another type of micro porous membrane is the track-etched membrane. This type of membrane is prepared by irradiating a polymer film with charged particles that attack the polymer chains, leaving damaged molecules behind. The film is then passed through an etching solution, and the damaged molecules dissolve to produce cylindrical pores, many of which are perpendicular to the membrane surface. A less common micro porous membrane is an expanded film membrane. Expanded film membranes are oriented crystalline polymers with voids created by an extrusion and stretching process. First, the material is extruded near its melting temperature using a rapid draw-down rate. Then, the extruded material is cooled, annealed, and stretched up to $300 \%$ of its original length. Isotropic membranes can also be dense films which either lack pores or contain pores that are so small as to render the membrane effectively non-porous. These films are prepared by solution casting followed by solvent evaporation or melt extrusion.
Dr.Komal P. Mehta et. al. [3] suggested a solution to meet the growing water requirements, along with the waste water from municipal sewage treatment plant, it is going to be a need for thinking the reuse of waste water from the industries wherever possible. It has already been started in some of the big industries especially in metro cities and it must be implemented at all level possible industries. Examples are textile industry, pharmaceutical industry, food and beverage industry where reuse of waste water is in consideration.

\section{DESIGN AND SETUP}

\section{A. Design:}

The following steps are taken to design a membrane system:

Step 1: Consider feed source, feed quality, feed flow rate, and required product quality:

The membrane system design depends on the available feed water and the application.

feed source: Canal Water

- feed quality:

- $\mathrm{TDS}=70-250 \mathrm{ppm}$

- Hardness $=50-200 \mathrm{ppm}$

- Silica $=10-35 \mathrm{ppm}$

required product quality:

- $\mathrm{TDS}=15-30 \mathrm{ppm}$

- Hardness = 5-12 ppm

- Silica $=2-5 \mathrm{ppm}$

Required Flow Rate: $30 \mathrm{~m}^{3} / \mathrm{hr}$

\section{Step 2: Select the membrane size}

It is selected on the basis of factory requirement for preventing the growth of bacteria or to prevent formation colonies of bacteria. Also if pores size of membrane becomes very small then there may be damage to membrane. As we go smaller and smaller then pressure required is increases as shown in graph. This pressure is harmful to membrane, there may be more wastage of water, also size of plant increases.

It is selected on the basis of fig: 4

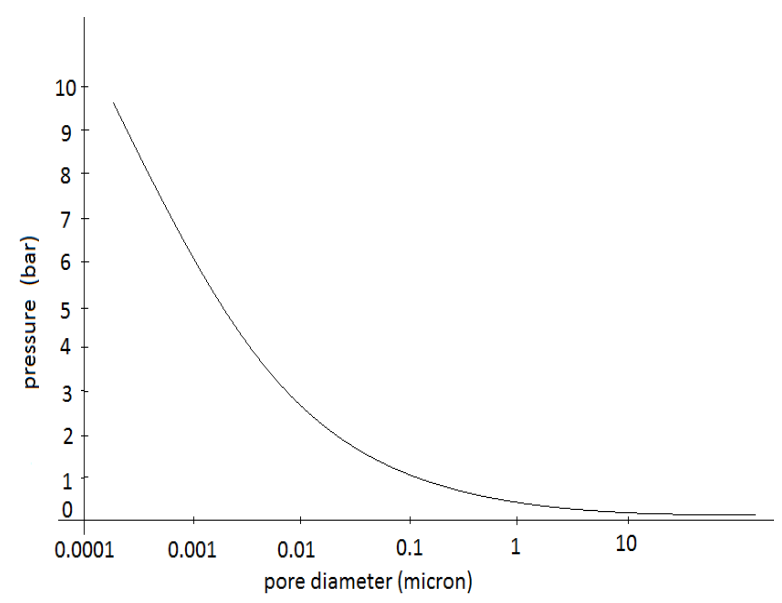

Fig.4. Graph of pressure vs pore diameter 
IARJSET

International Advanced Research Journal in Science, Engineering and Technology

National Conference on Design, Manufacturing, Energy \& Thermal Engineering (NCDMETE-2017)

AGTI's Dr. Daulatrao Aher College Engineering, Vidyanagar Extension, Karad

Vol. 4, Special Issue 1, January 2017

Referring above graph we consider membrane pore size 0.001 to 0.002 micron.

\section{Step3: Consideration of pressure:}

We have selected pore diameter of membrane 0.001 micron and from graph and consider the optimum feed pressure.

Feed pressure $\approx 6$ bar

..(From fig: 4)

Step 4: Select number of passes:

The standard flow configuration for water desalination is plug flow, where the feed volume is passed once through the system. Concentrate recirculation is common to smaller systems used in commercial applications, as well as in larger systems when the number of elements is too small to achieve a sufficiently high system recovery with plug flow. Concentrate recirculation systems can also be found in special applications like process liquids and wastewater. Number of passes selected by referring table no. 1

Table:1 Selection of number of passes

\begin{tabular}{|l|l|c|c|}
$\begin{array}{l}\text { No. of } \\
\text { passes }\end{array}$ & $\begin{array}{l}\text { TDS (total } \\
\text { dissolved }\end{array}$ & $\begin{array}{c}\text { Hardness } \\
(\mathrm{ppm})\end{array}$ & $\begin{array}{l}\text { Silica } \\
(\mathrm{ppm})\end{array}$ \\
\hline
\end{tabular}

\begin{tabular}{|c|c|c|c|}
\hline & solids $)(\mathrm{ppm})$ & & \\
\hline 1 & $0-600$ & $0-450$ & $0-80$ \\
\hline 2 & $600-1300$ & $450-850$ & Onwards \\
\hline 3 & $1300-2700$ & $850-1500$ & - \\
\hline 4 & $2700-4000$ & $1500-3200$ & - \\
\hline 5 & $4000-9000$ & $3200-4700$ & - \\
\hline 6 & $9000-15000$ & $4700-6500$ & - \\
\hline 7 & $15000-30000$ & Onwards & - \\
\hline 8 & Onwards & - & - \\
\hline
\end{tabular}

Hence number of passes: 1 ... (By referring table no.1)

Step 5: Select membrane element type

$$
\begin{gathered}
N_{E}=\frac{Q_{p}}{q} \\
=\frac{30}{1.26} \\
=23.8 \\
N_{E} \approx 24
\end{gathered}
$$

Where,

$N_{E}=$ Number of elements.

$Q_{p}=$ Flow rate of required water $\left(\mathrm{m}^{3} / \mathrm{hr}\right)$.

$\mathrm{q}=$ Standard permeate flow rate.

Hence we selected Element type NF200 of diameter 200 mm \& length $1000 \mathrm{~mm}$

Table:2.Selection of element type

\begin{tabular}{|c|c|c|c|}
\hline Sr. no. & Element type & Diameter $(\mathrm{mm})$ & Permeate flow at standard test condition(q) (lit/hr) \\
\hline 1 & NF270 & $62.5,100,200$ & $134-2,300$ \\
\hline 2 & NF200 & $62.5,100,200$ & $73-1,260$ \\
\hline 3 & NF90 & $62.5,100,200$ & $83-1,620$ \\
\hline 4 & TW30 & 45 & $3.8-16$ \\
\hline 5 & TW30,TW30HP & $50,62.5,100$ & $16-500$ \\
\hline 6 & BW30 & $62.5,100,200$ & $120-1,660$ \\
\hline 7 & BW30LE & 100,200 & $320-1,830$ \\
\hline 8 & XLE & $62.5,100,200$ & $52-2,040$ \\
\hline 9 & SW30 & $62.5,100$ & $24-300$ \\
\hline 10 & SW30HR & 200 & 950 \\
\hline 11 & SW30HRLE & 200 & 1,200 \\
\hline 12 & SW30XLE & 200 & 1,400 \\
\hline
\end{tabular}

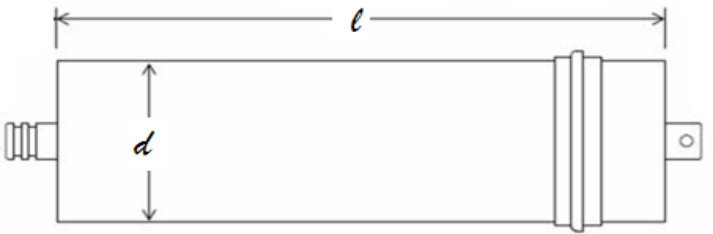

Fig.5. Membrane Element

Step 6: Calculate number of element vessels needed Divide the number of elements $N_{E}$ by the number of elements per element vessel, $N_{E E V}$, to obtain the number of element vessels, $N_{V}$ - round up to the nearest integer. For large systems, 6-element vessels are standard, but vessels with up to 8 elements are available.

$$
\begin{aligned}
N_{V} & =\frac{N_{E}}{N_{E E V}} \\
& =\frac{24}{6} \\
N_{V} & =4
\end{aligned}
$$

Where,

$N_{V}=$ Number of element vessel.

$N_{E}=$ Number of elements.

$N_{E E V}=$ Number of elements per element vessel. 


\section{B. Experimental Setup:}

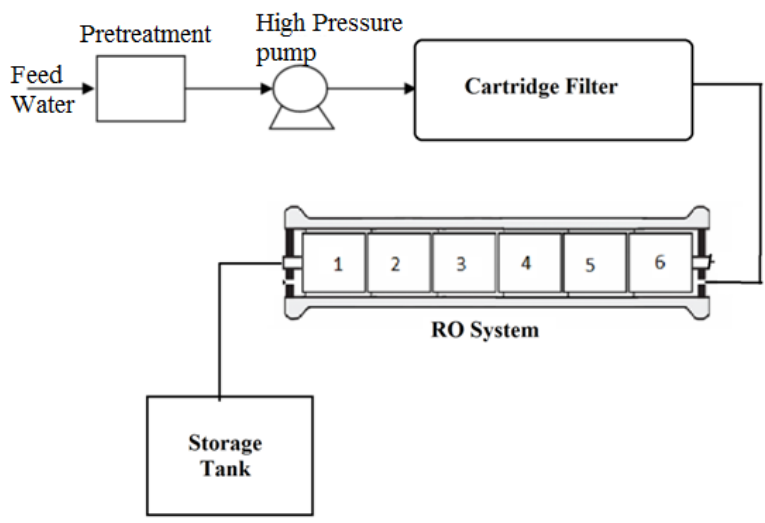

Fig.7.Experimental Setup

- Feed Water:Feed Water is the raw water required for plant, which comes from primary reservoirs like canal.

- Pretreatment: Large size impurities like dust particles,soil particles are removed by this process

- Cartridge filter:It is used remove impurities greater than 5 micron which are not removed by pretrement.

- RO System: RO System is used to remove very small impurities upto 0.001 micron.

- Storage tank:Storage tank is used to store the pure water obtained from RO plant.

\section{CONCLUSION}

As the pore diameter decreases pressure requirement increases.Feed water containing suspended particles, organic matter as well as inorganic salt may deposit on the membrane and fouling will occur or damage the membrane because of applied pressure and size of particles hence pressure should be optimum. If the sugar industries use this technique for boiler then there will be reduction in maintenance and increase in efficiency.

\section{REFERENCES}

[1] Barbara Kneen, Ann Lemley and Linda Wagnet, "R. O. treatment for drinking water", Water Treatment NOTES, November 2005.

[2] Sunil J. Kulkarni, Pallavi M. Kherde, "A Review on Advanced Membrane Separation Methods for Water Treatment", IJRR International Journal of Research and Review, 28 July 2015.

[3] Dr.Komal P.Mehta1, "Design of Reverse Osmosis System for reuse of waste water from Common Effluent Treatment Plant", International Research Journal of Engineering and Technology (IRJET), Volume: 02 Issue: 04, July-2015.

[4] Sukanchan Palit, "A Short Review of Applications of Reverse Osmosis and Other Membrane Separation Procedures", International Journal of Chemical Sciences and Applications, Vol 3, Issue 2, 2012.

[5] Garud R. M., Kore S. V., Kore V. S., Kulkarni G. S., "A Short Review on Process and Applications of Reverse Osmosis", Universal Journal of Environmental Research and Technology, Volume 1, Issue 3. 